\title{
IPM research profiled: 10-year trends
}

\section{Karen Klonsky $\square$ Ben Shouse}

W e surveyed principal investigators funded under the UC IPM

Competitive Grants Program to examine the evolution of the IPM Project from 1989 through 1999. Survey respondents helped us characterize the distribution of grants by commodity area and discipline, the degree of collaboration fostered, research goals and outcomes of research.

In the last decade, almost half of the projects funded involved fruit, nut or vegetable crops and another quarter addressed field crops. The remaining projects focused on livestock, nursery and flower crops, and urban or landscape pests or did not specify a commodity, focusing instead on general techniques. In all, 194 funded research projects investigated 45 different crops. By contrast, during the Project's first 10 years, it focused $80 \%$ of research funding on eight major crops or commodities (alfalfa, citrus, tomatoes, cotton, rice, grapes, walnuts and cereals).

\section{Collaboration}

Our data is based on completed surveys from $78 \%$ of the principal investigators to whom surveys were mailed, representing 153 of the 194 projects that received IPM grants between 1989 and 1999.

Entomology was the discipline most often included in the research projects $(45 \%)$ followed by plant pathology $(21 \%)$. Most $(70 \%)$ were managed by two or more investigators. While only 17 projects ( $9 \%$ ) involved principal investigators from different academic disciplines, 49 projects $(25 \%)$ involved principal investigators from different institutions (table 1). The rates of interdisciplinary cooperation and cross-institutional studies were lower than during the first 10 years of the program, when rates of $38 \%$ and $36 \%$ respectively, were identified (Grieshop and Pence 1990). From these results, it appears that collaboration of principal investigators is more likely

to occur within disciplines, but across institutions as researchers look beyond their own institutions to find co-investigators with the necessary technical expertise and interests to develop IPM research proposals.

Principal investigators reported receiving assistance from a variety of cooperators (table 2). Notable among these were UC farm advisors, who were the most frequent participants of any group in every stage of the research process except providing field trial space. They were seldom principal investigators on proposals although they were essential collaborators in developing proposals, managing field trials and collecting data. search projects either as individuals or through commodity groups. Field trial space was provided by growers for well over half of the IPM projects, and these growers assisted in managing almost one-third of those field trials. Clearly, the generous support of growers is critical to the research program funded by the UC IPM Program. However, growers were much less likely to be involved in data collection or interpretation of the results than in other aspects of the research either as individuals or through a commodity group.

Of other individuals and organizations outside of $U C$, representatives of commodity groups were twice as likely as growers, public agencies, or state-licensed pest control advisers (PCAs) to be involved in research proposal development, but none of these groups participated in more than 10\% of proposals in terms of field trial management, data collection or interpretation of results.

\section{Research outcomes}

The principal investigators responding said research outcomes in-
Growers can participate in the re- cluded publications, pest-control methods and equipment and computer decision aids. About two-thirds of the UC IPM research projects resulted in 480 publications of which 220 appeared in peer-reviewed journals. Web-based publications emerged from $10 \%$ of the projects. Virtually unknown 10 years ago, Web dissemination of information will undoubtedly continue to expand in the coming years.

While $30 \%$ of the projects resulted in nonchemical pest-control procedures, less than $10 \%$ developed synthetic chemical pest-control procedures, reflecting the general goal of UC IPM to develop strategies and tactics that permit pest managers and growers to move away from the use of synthetic pesticides toward biorational materials and other riskreducing approaches. Developing decision-making protocols and sampling procedures continue to be important goals of IPM research.

Fewer resources were directed toward developing computer programs for clientele than in the first 10 years of the program. This may reflect increasing sophistication of the general public in using software such as spreadsheets for their own decision making, increased use of the Web, and an increase in software development by the private sector.

\section{Pest-control methods developed}

During the 1990s, the USDA's National Agricultural Statistics Service began to classify growers' approaches to pest control as prevention, avoidance, monitoring and suppression, and this has become one tool for measuring IPM adoption. Preventative measures act to decrease the likelihood of an infestation through techniques such as using pest-free planting material, sanitation of equipment to avoid spreading weed seeds, destroying overwintering habitat for insects and 
irrigation scheduling to avoid disease infestations. Avoiding exposure to pests means planting resistant varieties, crop rotation to break pest cycles and choosing locations that are relatively pest-free. Suppression includes methods used in response to a pest outbreak to avoid reaching economically damaging levels. Monitoring is typically used in conjunction with suppression methods for information used in making the control decision.

Most of the research projects (77\%) included pest suppression as a method of pest control and $40 \%$ focused solely on pest suppression (table 3 ). The most common suppression method investigated was biocontrol/natural enemies ( $38 \%$ of projects), followed by chemical pesticides $(14 \%)$ and organically acceptable microbial and botanical pesticides $(13 \%)$. Over one-third of the projects developed monitoring procedures. One-fifth of the projects focused on avoidance practices such as use of resistant cultivars in an IPM program, crop rotation, timing of harvest and trap crops, while one-fifth focused upon cultural practices used to prevent infestations.

\section{Research goals}

Our analysis did not measure the adoption of IPM techniques, but rather documented the goals of the researchers. In many cases, the projects had multiple goals. Almost three-quarters of the projects were directed toward reducing pesticide use, and two-thirds of the projects were undertaken to improve the efficacy of pest control. Other frequently mentioned goals were lowering the cost of pest control, increasing the social acceptability of pest control systems, increasing the use of natural controls, and providing pest management methods for organic production. In particular, $39 \%$ of the projects developed methods appropriate for organic production.

The regulatory atmosphere that has evolved over the last decade to emphasize soft (environmentally benign) and risk-reducing approaches is a reflection of society's continuing concern for environmental and health impacts of continued use of broad-spectrum synthetic pesticides. IPM research hopefully will help growers and pest managers meet challenges posed by issues such as Food Quality Protection Act, loss of methyl bromide, the Clean Water Act's Total Maximum Daily Load Program, and, of course, profitability.

A challenge of the UC IPM Competitive Grants Program over the next 10 years will be to set priorities that will enable the development of practical soft and risk-reducing approaches that can be implemented by farmers and other pest control practitioners in California.

K. Klonsky is Extension Specialist, Department of Agricultural and Resource Economics, UC Davis; and B. Shouse is Postgraduate Researcher, Agricultural Issues Center, UC Davis.

\section{Reference}

Grieshop JI, Pence RA. 1990. Research results: Statewide IPM's first 10 years. Cal $\mathrm{Ag}$ 44(5): 24-6.

\begin{tabular}{|c|c|c|c|c|c|}
\hline \multirow[t]{2}{*}{ Institution } & \multicolumn{2}{|c|}{$\begin{array}{l}\text { Distribution among all } \\
\text { funded projects }(n=194)\end{array}$} & \multicolumn{3}{|c|}{$\begin{array}{l}\text { Distribution among projects } \\
\text { in survey response }(n=153)\end{array}$} \\
\hline & no. & $\%$ & \multicolumn{2}{|c|}{ no. } & $\%$ \\
\hline Cross-institution ${ }^{*}$ & 49 & 25 & \multicolumn{2}{|c|}{40} & 26 \\
\hline UC Davis & 60 & 31 & \multicolumn{2}{|c|}{48} & 31 \\
\hline UC Riverside & 41 & 21 & \multirow{2}{*}{\multicolumn{2}{|c|}{$\begin{array}{l}36 \\
20\end{array}$}} & 24 \\
\hline UC Berkeley & 32 & 17 & & & 13 \\
\hline Cooperative Extension & 4 & 2 & \multicolumn{2}{|c|}{3} & 2 \\
\hline Statewide IPM Project & 7 & 4 & \multicolumn{2}{|c|}{5} & 3 \\
\hline USDA & 1 & 1 & \multicolumn{2}{|c|}{1} & 1 \\
\hline \multicolumn{6}{|c|}{$\begin{array}{l}\text { Defined as more than one UC campus or Cooperative Extension office and } \\
\text { more than one academic department on the same campus. }\end{array}$} \\
\hline \multicolumn{6}{|c|}{$\begin{array}{l}\text { TABLE 2. Assistance provided by institutions and individuals at various stages } \\
\text { of the research process }(n=153)\end{array}$} \\
\hline Persons assisting & $\begin{array}{l}\text { Develop } \\
\text { research } \\
\text { proposal }\end{array}$ & $\begin{array}{l}\text { Provide field } \\
\text { trial space }\end{array}$ & $\begin{array}{l}\text { Manage } \\
\text { field trial }\end{array}$ & $\begin{array}{c}\text { Collect } \\
\text { data }\end{array}$ & $\begin{array}{r}\text { Interpret } \\
\text { results }\end{array}$ \\
\hline Growers & $20(10)^{*}$ & $106(55)$ & $51(26)$ & $13(7)$ & $10(5)$ \\
\hline Commodity groups & $41(21)$ & $7(4)$ & $9(5)$ & $3(2)$ & $5(3)$ \\
\hline Agencies & $16(8)$ & $8(4)$ & $8(4)$ & $7(4)$ & $7(4)$ \\
\hline PCAs & $23(12)$ & $15(8)$ & $17(9)$ & $9(5)$ & $5(3)$ \\
\hline Farm advisors & $75(39)$ & $37(19)$ & $56(29)$ & $50(26)$ & $43(22)$ \\
\hline IPM advisors & $22(11)$ & $6(3)$ & $13(7)$ & $13(7)$ & $14(7)$ \\
\hline Faculty & $54(28)$ & $10(5)$ & $12(6)$ & $20(10)$ & $42(22)$ \\
\hline CE specialists & $42(22)$ & $4(2)$ & $12(6)$ & $21(11)$ & $30(15)$ \\
\hline UC IPM staff & $3(2)$ & $1(1)$ & $0(0)$ & $2(1)$ & $5(3)$ \\
\hline
\end{tabular}

"Numbers in parentheses are percents of total number of projects.

TABLE 3. Methods of pest control developed by IPM research projects

\begin{tabular}{lcc}
\hline \hline Methods of pest control & Projects & $\%$ \\
& & \\
Prevention & 30 & 19 \\
Avoidance & 31 & 20 \\
Monitoring & 52 & 34 \\
Suppression: & $110^{*}$ & 77 \\
Natural enemies/biocontrol & 59 & 38 \\
Chemical pesticide & 22 & 14 \\
Microbial pesticide & 17 & 11 \\
Physical control (e.g., barriers, flooding, burning) & 16 & 10 \\
Spot/precision application & 16 & 10 \\
Reduced-risk pesticide & 13 & 8 \\
Cultivation and related techniques & 11 & 7 \\
Adjustment of planting density & 4 & 3 \\
Botanical pesticide & 3 & 2 \\
Mating disruption & 3 & 2 \\
Antibiotics & 1 & 1 \\
Genetic engineering & 1 & 1 \\
Other & 8 & 5 \\
\hline "Column entries and total do not match due to multiple responses. & &
\end{tabular}

